\title{
COLHEITA FRACIONADA E SEUS PRINCIPAIS BENEFÍCIOS NA CRIOPRESERVAÇÃO DO SÊMEN DE GARANHÕES
}

\author{
Sidnei Nunes de Oliveira ${ }^{1}$ \\ Endrigo Adonis Braga de Araujo ${ }^{2}$ \\ Luis Fernando Mercês Chaves Silva ${ }^{2}$ \\ Felipe Morales Dalanezi ${ }^{2}$ \\ Patrícia de Mello Papa ${ }^{1}$ \\ Bertiny Moreira Pinto ${ }^{3}$ \\ Luiz Roberto Pena de Andrade Junior ${ }^{2}$ \\ Frederico Ozanam Papa ${ }^{4}$
}

\begin{abstract}
RESUMO
As colheitas de sêmen em equinos são realizadas de forma convencional, com vagina artificial fechada, em que todas as frações se misturam. No entanto, a colheita de sêmen de forma fracionada, separa as diferentes frações do ejaculado, cada uma dessas frações possuem uma maior ou menor quantidade de plasma seminal, sendo as glândulas sexuais acessórias responsáveis por sua produção. Cada garanhão possui características individuais com relação à manutenção das células espermáticas durante a criopreservação, essas características podem estar relacionadas à produção do plasma seminal, assim como dos vários componentes. Sabese que existe um efeito deletério desempenhado pelos componentes do plasma seminal produzido principalmente pelas vesículas seminais, aos espermatozoides durante o processo de criopreservação, porém, esses fatores ainda são desconhecidos. Várias hipóteses são sugeridas, tais como, a redução na produção de lipídeos e os tipos de proteínas e íons presentes em cada uma das frações do ejaculado. Sabendo disso, a colheita fracionada pode trazer benefícios aos espermatozoides, de forma que as primeiras frações não tenham contato com o plasma seminal produzido pelas vesículas seminais, possibilitando uma melhor manutenção espermática durante a criopreservação.
\end{abstract}

Palavras-chave: equino, colheita fracionada, sêmen.

\section{FRACTIONATED COLLECTION AND THEIR MAIN BENEFITS IN THE STALLION SPERM CRYOPRESERVATION}

\begin{abstract}
Equine semen is collected by conventional way, with a closed artificial vagina, where all the fractions are mixed. However, semen collection discontinuously, separating the different fractions of the ejaculate, each of these fractions have a greater or lesser amount of seminal plasma, being the sex accessory glands responsible for their production. Each stud has individual characteristics with respect to the maintenance of sperm cells during the cryopreservation, these characteristics may be related to production of seminal plasma as well as the various components making up. It is known that there is a deleterious effect played by components of seminal plasma mainly produced by the seminal vesicles, the sperm cells

\footnotetext{
${ }^{1}$ Doutorando no Departamento de Reprodução Animal e Radiologia Veterinária. FMVZ-UNESP-Botucatu. Contato principal para correspondência.

2 Mestrado no Departamento de Reprodução Animal e Radiologia Veterinária. FMVZ-UNESP-Botucatu.

${ }^{3}$ Residente no Departamento de Reprodução Animal e Radiologia Veterinária. FMVZ-UNESP-Botucatu.

${ }^{4}$ Prof. Titular do Departamento de Reprodução Animal e Radiologia Veterinária. FMVZ-UNESP-Botucatu.
} 
during the cryopreservation process, however, these factors are still unknown. Several hypotheses are suggested such as reducing the production of lipids and proteins and the types of ions present in each fraction of the ejaculate. Knowing this, the fractional harvest can be beneficial to sperm, so that the first fraction have no contact with seminal plasma produced by the seminal vesicles, allowing for better maintenance sperm during cryopreservation.

Keywords: equine, fractionated collection, semen.

\section{COSECHA FRACCIONADA Y SUS PRINCIPALES BENEFICIOS EN LA CRIOPRESERVACIÓN DE SEMEN DE CABALLOS}

\section{RESUMEN}

Las cosechas convencionales de semen equino, son realizadas con vagina artificial cerrada, donde todas las fracciones seminales quedan mescladas. No obstante, la colecta de semen de forma dividida o fraccionada, separa las diferentes "fracciones" del eyaculado. Fracciones que contiene una mayor o menor cantidad de plasma seminal, siendo las glándulas sexuales accesorias responsables por su producción. Cada reproductor posee características individuales con relación al mantenimiento de las células espermáticas durante la criopreservación, características que pueden estar relacionadas a la producción del plasma seminal, o a alguno de sus componentes. Es conocido la existencia de un efecto deletéreo desempeñado por los componentes del plasma seminal, producido principalmente por las vesículas seminales a los espermatozoides durante el proceso de criopreservación. Sin embargo, esos factores se desconocen. Varias hipótesis son sugeridas, tales como, reducción en la producción de lípidos y los tipos de proteínas e iones presentes en cada una de las fracciones del eyaculado. Sabiendo esto, la cosecha fraccionada puede traer beneficios a los espermatozoides, de forma que las primeras fracciones no tengan contacto con el plasma seminal producido por las vesículas seminales, posibilitando una mejor manutención espermática durante la criopreservación.

Palabras claves: equino, cosecha fraccionada, semen.

\section{INTRODUÇÃO}

A inseminação artificial vem se tornando um pilar de sustentação e evolução na criação de equinos, tendo em vista que seu uso traz grandes benefícios na difusão do material genético de animais classificados como superiores, dentre eles, campeões em diversas modalidades de competição equestre.

Apesar do avanço no uso das biotécnicas reprodutivas, ainda há grandes desafios para melhorar os índices reprodutivos na equinocultura, principalmente quando estão relacionadas à criopreservação das células espermáticas em garanhões.

Estudos realizados indicam que o plasma seminal (PS) acarreta danos aos espermatozoides, culminando em prejuízos na qualidade espermática durante a refrigeração e a congelação (1), podendo diminuir os índices de fertilidade. Embora o plasma seminal possua um efeito negativo durante a criopreservação, existem também evidências do seu papel protetor às células espermáticas (2), dentre elas a prevenção da capacitação prematura que pode ser induzida durante o processo de congelação e descongelação (3), afirmando que, a presença de pequenas quantidades de PS parece ser necessária. Segundo Alghamdi et al. (4), a motilidade espermática é maior quando a proporção de PS é $\leq 5 \%$ antes da refrigeração e congelação, quando comparada a amostras com proporções entre 10-30\% no volume do 
ejaculado. Por outro lado, Jasko et al. (5) demonstram que a proporção ideal de PS no ejaculado seja em torno de 5 a $20 \%$, sem que haja um efeito prejudicial durante a criopreservação. Portanto, a centrifugação para retirada do PS faz-se necessária, principalmente para aqueles garanhões cujos ejaculados possuem baixa tolerância à criopreservação (1).

Assim, pressupõe-se que exista uma variação individual do efeito do PS entre garanhões (6) e da sua produção, existindo variações na composição do PS nas diferentes frações do ejaculado (7). Contudo, em estudos realizados, demonstrou-se que a fração rica em espermatozoides do ejaculado possui uma tolerância maior a criopreservação quando comparada às demais frações $(2,8)$.

Durante a colheita de sêmen de forma convencional, utilizando-se as vaginas artificiais modelo Missouri, Nishikawa, Hannover, Colorado ou Botucatu, todas as frações do ejaculado se misturam e não há possibilidade de separação destas. Diante disto, Varner et al. (9) sugerem que a colheita fracionada poderá reduzir o efeito deletério do PS ao colher apenas a fração rica em espermatozoides do ejaculado, correspondente a $75 \%$ do total de espermatozoides.

Desta forma, uma alternativa para minimizar as injúrias provocadas pelo PS em garanhões que produzem sêmen com tolerância limitada à criopreservação, seria a colheita de sêmen fracionada, possibilitando, com isso, identificar as diferentes frações e separar a fração espermática com maior percentual de espermatozoides em menor contato com o PS. O presente trabalho tem por objetivo revisar a colheita fracionada de sêmen em garanhões, assim como, seus benefícios para as células espermáticas que serão submetidas à criopreservação.

\section{REVISÃO DE LITERATURA}

\section{Principais Métodos de Colheita do Sêmen Equino}

\section{Estimulação Manual}

O processo de colheita de sêmen em garanhões se iniciou por volta de 1965, em que utilizava-se a estimulação manual do pênis com um saco plástico descartável sobre a extremidade do pênis para pegar o ejaculado (10-12). Em dias atuais, esse tipo de colheita pode ser utilizada em casos específicos, como por exemplo, em garanhões com paralisia de pênis ou com déficit de ereção (13). A partir disso, essa técnica foi aperfeiçoada e criou-se um modelo de vagina artificial caseiro, estilo Mississippi, composta por um tudo de borracha e látex, uma extremidade com duas camadas de espuma e um acolchoamento de borracha $(10,14)$.

\section{Colheita Convencional com Vagina Artificial}

Desde então, as colheitas de sêmen em equinos são realizadas por meio de uma vagina artificial, para a realização das colheitas o garanhão monta em manequim ou em uma égua em estro devidamente contida $(10,15)$.

Diversos modelos de vagina artificial (VA) foram criados, tais como: Hannover, Missouri, Nishikawa, Colorado, Botucatu, dentre outros modelos, e são empregadas usualmente na colheita convencional de ejaculados de garanhões em programas de reprodução assistida em todo o mundo. Basicamente, esses modelos de vaginas possuem um tubo rígido, uma mucosa interna de látex, que armazena o líquido para manutenção da temperatura interna, em torno de 44 e $50^{\circ} \mathrm{C}$, e um recipiente para armazenamento do sêmen 
(16,17). A partir do trabalho realizado por Lopes et al. (18), a maioria das colheitas de sêmen usualmente colocam uma mucosa sanitária interna de plástico, evitando o contato das células espermáticas com a mucosa de látex, que pode ser prejudicial aos espermatozoides, além de evitar a transmissão de doenças venéreas de um garanhão para outro durante as colheitas.

Apesar das vaginas artificiais convencionais serem as mais utilizadas na rotina dos haras a nível mundial, por serem de fácil utilização e praticidade, não representam uma situação fisiológica da monta natural, assim, no volume total da ejaculação, todos os fluidos se misturam em um recipiente único $(19,20)$.

Um ponto crítico da utilização da colheita de forma convencional está relacionada à contaminação bacteriana, de forma que, neste modelo de colheita, o líquido pré-seminal, assim como todos os jatos de sêmen, se misturam, entrando em contato direto com o pênis, que poderá levar a contaminação do ejaculado, o que justifica a frequência de isolamento bacteriano sem evidência de infecção no ejaculado total $(21,22)$.

\section{Alternativas de Colheita de Sêmen em Equinos}

Outras formas de colheita de sêmen mencionadas na literatura são: a colheita de sêmen com o animal em estação, indicada para aqueles com problemas do sistema músculo esquelético ou com lesões neurológicas, impossibilitado-os de realizar a monta, principalmente quando ocorre em animais idosos $(10,13,15)$; por indução farmacológica, utilizado para aqueles garanhões com distúrbios ejaculatórios, fraturas ósseas com imobilização de algum membro, disfunção erétil, paralisia de pênis, em que opta-se pela utilização de fármacos alfa-adrenérgicos $(13,23)$, além de detomidina, prostaglandina e ocitocina, que também têm sido estudados $(12,23)$; e a colheita de sêmen da cauda do epidídimo, para garanhões com morte inesperada, causada por cólicas, acidentes traumáticos ou em problemas relacionados à manutenção dos testículos, como na hérnia escrotal, ou outras situações que comprometam a utilização futura do material genético (24-27).

\section{COLHEITA FRACIONADA DO SÊMEN EQUINO}

Inicialmente, a colheita fracionada do sêmen equino, com o uso de vagina artificial aberta, foi descrita por Mann et al. (28), em que foram determinadas as primeiras divisões do ejaculado nas frações pré-espermática, rica em espermatozoides, pobre em espermatozoides e gelatinosa. Esse modelo de vagina artificial permite a separação das diferentes frações do ejaculado de acordo com os jatos de sêmen, podendo ser usado como um método diagnóstico de patologias das glândulas sexuais acessórias e/ou do pênis, além de permitir uma colheita de sêmen com uma menor contaminação bacteriana.

Em 1974, Tischner et al. (19),objetivando obter mais informações sobre o padrão copulatório e ejaculatório dos garanhões, realizaram colheitas com o uso de vagina artificial aberta, a qual denominaram de modelo Kraków-72. A partir deste trabalho, pode-se compreender melhor o processo ejaculatório dos equinos.

Varner et al. (9) utilizando uma adaptação do modelo proposto por Tischner et al. (19) e utilizaram uma vagina artificial modelo Missouri desprovida do copo coletor que fica acoplado no final da vagina, com isso, o ejaculado foi dividido em duas frações, a primeira composta pelos três primeiro jatos de sêmen e a segunda, o restante do ejaculado, sendo colhidas em recipientes diferentes.

Em 1993, um modelo de manequim com simulador de colheita fracionada computadorizado foi desenvolvido na Finlândia, com o objetivo de separar as frações seminais e minimizar a contaminação da fração rica em espermatozoides, denominado de Equidame $^{\circledR}(29)$. É composto internamente por uma vagina artificial e acoplada a ela há um 
funil metálico, logo abaixo, existe uma bandeja coletora de sêmen que possui cinco compartimentos onde são encaixados os recipientes de colheita conectados a um computador e, à medida que vão sendo preenchidos com o peso programado correspondente a cada fração do ejaculado, essa bandeja se move horizontalmente, sendo necessário apenas uma pessoa para a realização da colheita (29). Apesar de inovador, seu custo parece ser bastante elevado, um fator limitante à sua acessibilidade.

Outro modelo de vagina artificial aberta para colheita fracionada foi criado por Fonseca (17), denominada de vagina experimental articulada, composto por um dispositivo fracionador que separa o líquido pré-espermático no primeiro copo, em seguida, os três primeiros jatos num segundo copo e o restante do ejaculado novamente no primeiro copo, separando, assim, em duas porções.

Em 2011, Kareskoski (30) comparou a colheita fracionada pelo Equidame ${ }^{\circledR}$ à utilização da vagina artificial modelo Missouri com um funil acoplado a uma bainha de "probe", em que as frações são separadas por pinças, demonstrando que não houve diferença entre os dois métodos.

Apesar de várias formas e modelos de colheitas fracionadas estarem descritos na literatura, ainda é pouco utilizada na rotina, em alguns casos por se tratar de uma técnica laboriosa ou pela falta de um método prático que se adeque tanto em pesquisas quanto aos profissionais que trabalham à campo.

\section{Benefícios da Colheita Fracionada do Sêmen Equino}

Em comparação ao método tradicional, a vagina artificial aberta possui algumas vantagens assim como, desvantagens. De acordo com Jasko et al. (5), o plasma seminal possui um efeito deletério sobre a viabilidade das células espermáticas e, sabendo das características ejaculatórias do equinos, por meio de trabalhos descritos a colheita fracionada começou a ser utilizada como uma alternativa para minimizar as injúrias provocadas pelo plasma seminal, sendo também uma opção à centrifugação para retirada do PS, que acarreta danos aos espermatozoides intolerantes a esta técnica.

Varner et al. (9) relatam a utilização da colheita fracionada como forma de eliminar o contato do plasma seminal produzido pelas vesículas seminais, com a fração rica em espermatozoides e com isso, melhorar a longevidade espermática, desta forma, foram colhidos apenas os três primeiros jatos de sêmen e observou-se que inicialmente não há diferença de motilidade entre a fração rica em espermatozoides comparada ao ejaculado total, porém, houve diferença estatística na motilidade total e progressiva após algumas horas de incubação. Achados semelhantes foram reportados por Kareskoski et al. (2), sendo a motilidade total da fração rica superior ao ejaculado total pós-descongelação. A partir disso, pode-se concluir que existe um efeito deletério do plasma seminal nas células espermáticas ainda não elucidados e, com o passar do tempo, o contato prejudica ainda mais a viabilidade espermática.

Além disso, também há evidências de que a colheita fracionada diminui a contaminação bacteriana do ejaculado, como demonstrado por Tischner et al. (19), em que os jatos foram separados individualmente e não observou-se crescimento bacteriano em nenhuma das frações, ao contrário do observado nas amostras de ejaculado total, que apresentaram elevado grau de contaminação, além de ressaltar a eficiência na separação exata das frações do ejaculado por meio da colheita fracionada.

Lindeberg et al. (29) relataram uma diferença estatística significativa das unidades formadoras de colônias (UFC) após a refrigeração, por um período de $24 \mathrm{~h}$, quando a colheita foi realizada de forma convencional, com a vagina artificial Missouri, em comparação ao modelo Equidame ${ }^{\circledR}$ de colheita fracionada entretanto, após um período de 48 h, não foram 
encontradas diferenças significativas entre os dois métodos. Em relação à contagem de UFC entre as frações pré-espermáticas e rica em espermatozoides, colhidos por meio do Equidame $^{\circledR}$, não houve diferença e poucas UFC foram isoladas (29). Além disso, quando esses mesmos autores compararam os valores de motilidade total e progressiva entre os métodos de colheita, não houve diferença estatística significativa 24 ou $48 \mathrm{~h}$ após a refrigeração e após a descongelação.

Uma redução das UFC também foi reportada por Fonseca (17), quando os ejaculados foram colhidos fracionados com a vagina artificial articulada, ao contrário do observado no ejaculado total, colhido pelo método convencional, apresentando uma elevação das UFC. Porém, esse trabalho não mostrou diferença significativa entre a cinética espermática da fração rica e a fração pobre em espermatozoides logo após as colheitas.

Sieme et al. (8), demonstraram que os primeiros três jatos de sêmen colhidos fracionados e centrifugados para a congelação diferenciaram positivamente em termos de integridade de membrana e motilidade progressiva após a descongelação.

Diferentes resultados foram obtidos por Akcay et al. (6), que afirmaram haver uma superioridade na integridade de membrana para um "pool" de espermatozoides das demais frações do ejaculado, separados por meio do Equidame ${ }^{\circledR}$ quando comparado à fração rica em espermatozoides, já em relação à motilidade progressiva, não houve diferença entre o "pool" e a fração rica.

Resultados semelhantes foram sugeridos por Kareskoski et al. (2), estes compararam as diferentes frações do ejaculado fracionado, colhidos com o Equidame ${ }^{\circledR}$, após a remoção do PS por centrifugação e ressuspensão em meio de refrigeração, com as mesmas frações, sem a retirada do PS e apenas diluídas em meio à base de leite. Os resultados mostraram uma redução da motilidade dos espermatozoides em amostras que o PS foi removido, portanto, os autores sugerem existir uma interação positiva da motilidade com a presença de PS.

Kareskoski (30) encontrou um percentual elevado de fragmentação do DNA nas frações rica, pobre e a fração correspondente ao ejaculado total quando as amostras foram refrigeradas com a presença do PS. Apesar disso, não foram encontradas diferenças entre os parâmetros de motilidade total e progressiva entre as diferentes frações do ejaculado após a refrigeração.

Além dos benefícios da colheita fracionada anteriormente citados, uma nova abordagem de extrema importância desse método faz-se necessário para garanhões com vesiculite. Desta forma, a colheita fracionada foi relatada com sucesso na recuperação de espermatozoides de um garanhão com piospermia $(31,32)$. Como a fração contaminada do ejaculado é a terceira, produzida pela vesícula seminal, acredita-se que as primeiras frações de sêmen são isentas de contaminação ou pouco contaminadas, tornando possível a recuperação do sêmen para posterior utilização para criopreservação.

\section{CONSIDERAÇÕES FINAIS}

Apesar das diferentes abordagens e achados a respeitos dos benefícios da utilização da colheita fracionada de sêmen de garanhões, os resultados ainda são inconsistentes. Acreditase que existam benefícios, porém, talvez tenha relação com a individualidade de cada garanhão.

Quando as células espermáticas são prejudicadas pelo plasma seminal, a colheita fracionada é o método mais indicado para reduzir esse efeito deletério exercido nos espermatozoides.

Para garanhões com oligospermia, a colheita fracionada torna-se um método eficiente para concentrar as células espermáticas do ejaculado, reduzindo os possíveis danos mecânicos provocados pela centrifugação. Como técnica diagnóstico e recuperação de células 
espermáticas em garanhões com patologias das glândulas sexuais acessórias, essa técnica torna-se uma alternativa de grande aplicabilidade. Apesar das inúmeras vantagens, mais estudos são necessários para aperfeiçoar a técnica da colheita fracionada.

Apoio e financiamento Agência FAPESP.

\section{REFERÊNCIAS}

1. Kareskoski AM, Katila T. Components of stallion seminal plasma and the effects of seminal plasma on sperm longevity. Anim Reprod Sci. 2008;10:249-56.

2. Kareskoski AM, Reilas T, Andersson M, Katila T. Motility and plasma membrane integrity of spermatozoa in fractionated stallion ejaculates after storage. Reprod Domest Anim. 2006;41:33-8.

3. Schembri MA, Major DA, Suttie JJ, Maxwell WM, Evans G. Capacitation-like changes in equine spermatozoa throughout the cryopreservation process. Reprod Fertil Dev. 2002;14:225-33.

4. Alghamdi AS, Troedsson MH, Xue JL, Crabo BG. Effect of seminal plasma concentration and various extenders on postthaw motility and glass wool-Sephadex filtration of cryopreserved stallion semen. Am J Vet Res. 2002;63:880-5.

5. Jasko DJ, Hathaway JA, Schaltenbrand VL, Simper WD, Squires EL. Effect of seminal plasma and egg yolk on motion characteristics of cooled stallion spermatozoa. Theriogenology. 1992;37:1241-52.

6. Akcay E, Reilas T, Andersson M, Katila T. Effect of seminal plasma fractions on sperm survival after cooled storage. J Vet Med A Physiol Pathol Clin Med. 2006;53:481-5.

7. Katila T, Reilas T, Guvenc K, Alm K, Andersson M. The effect of seminal plasma on motility characteristics and viability of spermatozoa after cooled storage. In: Proceedings of the 3rd Meeting of the EEGG; 2004; Suffolk, UK. Suffolk: EEGG; 2004. p.3-5.

8. Sieme H, Katila T, Klug E. Effect of semen collection practices on sperm characteristics before and after storage and on fertility of stallions. Theriogenology. 2004;61:769-84.

9. Varner DD, Blanchard TL, Love CL, Garcia MC, Kenney RM. Effects of semen fractionation and dilution ratio on equine spermatozoal motility parameters. Theriogenology. 1987;28:709-18.

10. Crump Jr J, Crump J. Stallion ejaculation induced by manual stimulation of the penis. Theriogenology. 1989;31:341-6.

11. McDonnell SM, Love CC. Manual stimulation collection of semen from stallions: training time, sexual behavior and semen. Theriogenology. 1990;33:6.

12. McDonnell SM. Ejaculation physiology and dysfunction. Vet Clin North Am Equine Pract. 1992;8:57-70. 
13. McDonnell SM. Techniques for extending the breeding career of aging and disabled stallions. Clin Tech Equine Pract. 2005;4:269-76.

14. Berliner V. Horses and Jackstock. In: Perry EJ. The artificial insemination of farm animals. New Brunswick, NJ: Rutgers University Press; 1960.

15. Schumacher J, Riddell MG. Collection of stallion semen without a mount. Theriogenology. 1986;26:245-50.

16. McKinnon AO, Voss JL. Equine reproduction. Philadelphia: Lea and Febiger; 1992.

17. Fonseca $\mathrm{CW}$. Efeito de uma nova técnica de coleta fracionada sobre a composição do plasma seminal e qualidade do sêmen equino pós-descongelamento [dissertação]. Campos dos Goytacazes: Universidade estadual do norte fluminense Darcy Ribeiro; 2006.

18. Lopes MD, Papa FO, Martino AP, Bicudo SD, Alvarenga MA. Efeito do tipo de mucosa de vagina artificial sobre a qualidade espermática de garanhões. Rev Bras Reprod Anim. 1997;21:29-34.

19. Tischner M, Kosiniak K, Bielanski W. Analysis of the pattern of ejaculation in stallions. J Reprod Fertil. 1974;41:329-35.

20. Rodríguez-Martínez H, Kvist U, Ernerudh J, Sanz L, Calvete JJ. Seminal plasma proteins: what role do they play? Am J Reprod Immunol. 2011;66:11-22.

21. Tischner M, Kosiniak K. Techniques for collection and storage of stallion semen with minimal secondary contamination. Acta Vet Scand. 1992;88:83-90.

22. Silva KMG, Papa FO, Gabaldi SH, Crocci AJ. Efeito dos antibióticos gentamicina e cefalotina e do aminoácido taurina em meio de gema de ovo (Baken), sobre a longevidade e fertilidade do sêmen resfriado de equino. Rev Bras Cienc Vet. 2003;10:817.

23. McDonnell SM. Oral imipramine and intravenous xylazine for pharmacologicallyinduced ex copula ejaculation in stallions. Anim Reprod Sci. 2001;68:153-9.

24. Papa FO, Melo CM, Fioratti EG, Dell'Aqua Jr. JA, Zahn FS, Alvarenga MA. Freezing of stallion epididymal sperm. Anim Reprod Sci. 2008;107:293-301.

25. Heise A, Thompson PN, Gerber D. Influence of seminal plasma on fresh and post-thaw parameters of stallion epididymal spermatozoa. Anim Reprod Sci. 2011;123:192-201.

26. Monteiro GA, Papa FO, Zahn FS, Dell'Aqua Jr. JA, Melo CM, Maziero RRD, et al. Cryopreservation and fertility of ejaculated and epididymal stallion Sperm. Anim Reprod Sci. 2011;127:197-201.

27. Monteiro GA, Guasti PN, Rocha AS, Martin I, Sancler-Silva YFR, Freitas Dell'Aqua CP, et al. Effect of storage time and temperature of equine epididymis on the viability, motion parameters, and freezability of epididymal sperm. J Equine Vet Sci. 2013;33:169-73. 
28. Mann T, Short RV, Walton A. The 'tail-end sample' of stallion semen. J Agric Sci Cambridge. 1957;49:301.

29. Lindeberg H, Karjalainen H, Koskinen E, Katila T. Quality of stallion semen obtained by a new semen collection phantom (equidame ${ }^{\circledR}$ ) versus a missouri ${ }^{\circledR}$ artificial vagina. Theriogenology. 1999;51:1157-73.

30. Kareskoski AM. Components of fractionated stallion seminal plasma and the effects of seminal plasma on sperm longevity [dissertação]. Helsinki: Faculty of Veterinary Medicine, University of Helsinki Finland; 2011.

31. Oliveira SN, Araujo EAB, Chaves-Silva LFM, Andrade Jr LRP, Dalanezi FM, Pinto BM, et al. Eficiência de uma nova técnica de coleta de sêmen para diagnóstico e controle de piospermia em garanhões: relato de caso. In: Anais da 16a Conferência Anual da ABRAVEQ; 2015; Águas de Lindóia. Águas de Lindóia: ABRAVEQ; 2015.

32. Oliveira SN, Andrade Jr. LRP, Chaves-Silva LFM, Araujo EAB, Dalanezi FM, Papa PM, et al. Novo método de colheita fracionada de sêmen para melhoria da fertilidade em garanhão com vesiculite seminal. In: Anais da 17a Conferência Anual da ABRAVEQ; 2016; Campos do Jordão. Campos do Jordão: ABRAVEQ; 2016.

Recebido em: 18/10/2016

Aceito em: 04/06/2017 